\title{
miR-17-92 plays an oncogenic role and conveys chemo-resistance to cisplatin in human prostate cancer cells
}

\author{
PENG ZHOU $^{1 *}$, LIANG MA $^{1 *}$, JUN ZHOU $^{1}$, MIN JIANG $^{3}$, ENYU RAO $^{2}$, YONG ZHAO $^{2}$ and FENG GUO \\ ${ }^{1}$ Central Laboratory, The First Affiliated Hospital of Soochow University, Suzhou, Jiangsu 215006; \\ ${ }^{2}$ State Key Laboratory of Biomembrane and Membrane Biotechnology, Institute of Zoology, \\ Chinese Academy of Sciences, Beijing 100101; ${ }^{3}$ Department of Blood Transfusion, The First \\ Affiliated Hospital of Soochow University, Suzhou, Jiangsu 215006, P.R. China
}

Received January 8, 2016; Accepted February 4, 2016

DOI: $10.3892 /$ ijo.2016.3392

\begin{abstract}
The mir-17-92 cluster consists of six mature miRNAs and is implicated in diverse human cancers by targeting mRNAs involved in distinct pathways that either promote or inhibit carcinogenesis. However, the molecular mechanism underlying the mir-17-92 cluster-mediated pro-tumorigenic or anti-tumorigenic effects has not been clearly elucidated in prostate cancer. In the present study, the role of the mir-17-92 cluster in diverse aspects of prostate cancer cells has been thoroughly investigated. Forced introduction of the mir-17-92 cluster into the androgen-independent DU145 prostate cancer cells evidently promoted cell growth due to disruption of the balance between cellular proliferation and apoptosis. Overexpression of the mir-17-92 cluster significantly improved the migration and invasion of the DU145 cells, attributed to the induction of integrin $\beta-1$. Notably, the mir-17-92 cluster conveyed chemo-resistance to cisplatin. We demonstrated that the mir-17-92 cluster suppressed the expression of inhibitor of the AKT signaling pathway and activated the AKT pathway subsequently, which played a central role in regulating cellular proliferation, apoptosis and chemo-resistance. Continuously activated ERK1/2 signaling also contributed importantly to these processes. The present study provides key evidence for crucial oncogenic role of the $m i R-17-92$ cluster in prostate
\end{abstract}

Correspondence to: Dr Feng Guo, Central Laboratory, The First Affiliated Hospital of Soochow University, Shizi Road 188, Suzhou, Jiangsu 215006, P.R. China

E-mail: guofeng27@suda.edu.cn

Dr Yong Zhao, State Key Laboratory of Biomembrane and Membrane Biotechnology, Institute of Zoology, Chinese Academy of Sciences, Beichen West Road 1-5, Chaoyang, Beijing 100101, P.R. China

E-mail: zhaoy@ioz.ac.cn

*Contributed equally

Key words: miR-17-92, cell growth, chemo-resistance, migration, invasion cancer cells. Further investigations are warranted to determine whether $m i R-17-92$ cluster can be targeted for future treatment of human prostate cancer.

\section{Introduction}

Prostate cancer is the most frequently diagnosed male malignancy and one of the leading causes of death among men in western countries, and its incidence has been rising in China during the past few years. However, the precise molecular mechanisms underlying the progression of prostate cancer are still underexplored. It is generally considered that the carcinogenesis of prostate is a consequence of genetic and epigenetic modifications, converting normal prostate glandular epithelium to pre-neoplastic lesions and invasive carcinoma at the final stage. It is essential to develop more specific diagnostic and prognostic biomarkers for predicting the severity of prostate cancer, which demands a better understanding of the molecular pathogenesis of prostate cancer (1).

Recent studies suggest that microRNAs (miRNAs) are significantly altered in prostate cancer, suggesting that miRNAs are involved in the progression of prostate cancer. As naturally occurring small non-coding RNAs $(\approx 22$ nucleotides), miRNAs bind to the complementary sites in the 3' untranslated regions (3' UTRs) of targeting mRNAs and further regulate either translational inhibition or mRNA degradation. miRNAs have been implicated in controlling a wide range of cellular processes such as cell cycle, proliferation and apoptosis, differentiation and development and metabolism. Importantly, aberrant expression of miRNAs can cause diverse human disorders, especially malignancies. In fact, miRNAs act as either tumor suppressors or oncogenes, and participate in the development of a variety of malignancies in a tissue-specific manner. Distinct miRNAs that are either upregulated or downregulated in prostate cancer have been identified in a few microarray assays by comparing with normal prostate tissue. Considerable miRNA profiling data indicate a relationship of miRNA expression patterns with carcinogenesis or degree of cancer differentiation in prostate cancer. The specific miRNA expression patterns might be useful biomarkers for early detection and prognostic assessment of prostate cancer (2-4). However, the precise role of 
specific miRNAs in regulating the carcinogenesis of prostate cancer is still largely unclear.

The mir-17-92 cluster, which is also designated as oncomir-1, is one of the best-characterized oncogenic miRNAs (5). Human miR-17-92 is located within intron 3 of the C13orf 25 gene at $13 q 31.3$, a region frequently amplified in many hematopoietic and solid malignancies (6). The distinct six mature miRNAs encoded by mir-17-92 are classified into three separate miRNAs families, the $m i R-17$ family (including $m i R-17, m i R-18$ and $m i R-20$ ), the $m i R-19$ family (including $m i R-19 a$ and $m i R-19 b)$ and the $m i R-92$ family.

The mir-17-92 cluster is expressed in embryonic cells and essential in normal development. Dysregulation of the mir-17-92 cluster has been found in multiple hematopoietic and solid malignancies such as those derived from breast, lung, pancreas, kidney, colon, liver, stomach and prostate (7-13). In general, the mir-17-92 cluster functions as oncogenes and promotes carcinogenesis by negatively regulating tumor suppressors and/or genes that control a variety of biological behaviors such as cell cycle, cell proliferation and survival $(8,14)$.

The mir-17-92 cluster has been ascribed an oncogenic role in prostate cancer. In primary prostate cancer tissues, $m i R-17$ and $m i R-20$ are overexpressed compared to that in benign prostate tissues (7). Moreover, $m i R-20$ expression is significantly higher in patients with a high Gleason score than patients with a low score (15). The individual member of the mir-17-92 cluster has a characteristic expression profile in different prostate cancer cell lines (16). Overexpression of $m i R-20$ decreases apoptosis in a prostate cancer cell line, while inhibition of $m i R-20$ by an antisense oligonucleotide results in increased cell death after doxorubicin treatment (17). Recent studies have demonstrated that the aberrant expression of miRNAs, including $m i R-17, m i R-20, m i R-92, m i R-106 a / b$, $m i R-125$ and $m i R-145$ is involved in prostate cancer onset, progression, and metastasis (18). Nevertheless, the precise role of the miR-17-92 cluster in modulating malignant progression of prostate cancer is poorly understood.

In the present study, we investigated the functional roles of the mir-17-92 cluster in prostate cancer cells and examine its significance as a therapeutic target. The expression pattern of the androgen-independent prostate cancer cells was quite different from that of the androgen-dependent cells. Forced introduction of the miR-17-92 cluster into DU145 androgenindependent prostate cancer cells affected a variety of biological behaviors of cells. The stimulatory function of this miRNA cluster in prostate cancer cell growth, migration and invasion and chemo-resistance were observed. Activated protein kinase B (PKB, also known as AKT) and extracellular-signal-regulated kinase (ERK) signaling pathways played critical roles in these cellular processes. Collectively, we provided evidence that the mir-17-92 cluster functioned as an oncogene in prostate cancer and could possess potential for targeted therapy in human prostate cancer.

\section{Materials and methods}

Tissue culture. Cells were cultured in RPMI-1640 media supplemented with $10 \%$ fetal bovine serum (FBS), $100 \mathrm{U} / \mathrm{ml}$ penicillin, $100 \mu \mathrm{g} / \mathrm{ml}$ streptomycin and $2 \mathrm{mM}$ glutamine.
All cell lines were maintained in a humidified atmosphere containing $5 \% \mathrm{CO}_{2}$ at $37^{\circ} \mathrm{C}$. MG-132 (cat. no. 474790) was purchased from Millipore. Cisplatin (cat. no. 029K1426) was purchased from Sigma-Aldrich. Puromycin (cat. no. J593) was purchased from Amresco.

Transfection. The miR-17-92 cluster overexpression vector was constructed on a backbone of MSCV vector containing GFP (gift from Professor Yong Zhao). Phoenix A packaging cells were transfected with MSCV-GFP-miR-17-92 or control vector (MSCV-GFP) by FuGene HD (Roche, Shanghai, China). Virus supernatants were collected and target cells were infected with the virus supernatants. For obtaining stable expressing cells, the cells were selected for two weeks in the presence of puromycin $(5 \mu \mathrm{g} / \mathrm{ml})$.

RNA extraction. Total RNA was isolated using the TRIZol reagent (Tiangen Biotech, Co., Ltd., Beijing, China) according to the manufacturer's instructions. RNA yield and purity were determined spectrophotometrically at 260-280 $\mathrm{nm}$ and the integrity of RNA was verified by NanoDrop 1000 (Thermo Fisher Scientific, Co., Ltd., Shanghai, China).

Quantitative reverse-transcriptase polymerase chain reaction ( $q R T-P C R)$. Total RNA (2 $\mu \mathrm{g})$ was reverse-transcribed with SuperScript M-MLV (Promega, Shanghai, China) according to the manufacturer's instructions. Triplicates were performed for all qRT-PCR reactions with a LightCycler 480 System (Roche). Primers were designed using Primer-BLAST (PubMed) and synthesized from Invitrogen (Beijing, China). The cDNAs were amplified using 2X LC480 SYBR-Green I Master Mix (Roche). Data were analyzed with the Pfaffl method that provides a means for quantification of a target gene transcript in comparison to a reference gene (19). Primer sequences are as follows: BIM: 5'-ACAGAGCCACAAGAC AGGAGCCC-3' and 5'-CGCCGCAACTCTTGGGCGAT-3'; CCND1: 5'-CACTTTCAGTCCAATAGGTGTAG-3' and 5'-TTCTTCTTGACTGGCACG-3'; PTEN: 5'-TGGGGAAGT AAGGACCAGAGA-3' and 5'-TGAGGATTGCAAGTTC CGCC-3'; PHLPP2: 5'-GTACGCAAGGGAAAGACCCA-3' and 5'-AGCAAGGGAGTATTGCCGTC-3'.

qRT-PCR analysis of mature miRNA expression. Total RNA $(2 \mu \mathrm{g})$ was polyadenylated with ATP by E. coli poly(A) polymerase (PAP; New England Biolabs, Ltd., Beijing, China). After phenol-chloroform extraction and ethanol precipitation, the polyadenylated RNAs were dissolved in diethyl-pyrocarbonate (DEPC)-treated water and reverse-transcribed with M-MLV and universal RT primer sequence. After a dilution of 1:20, the cDNAs were amplified using 2X LC480 SYBR-Green I Master Mix. The mean threshold cycle $(\mathrm{Ct})$ was determined from triplicates. U6 expression was used as an internal control. Data were analyzed with the Pfaffl method (19).

Western blot analysis. Whole-cell extracts and nuclear/ cytoplasm fractions were prepared according to the standard procedures. Proteins were fractionated on an SDS-PAGE gel and transferred to nitrocellulose membranes. After blocking, membranes were probed with different antibodies (Abs). Membranes were then washed and incubated with an appro- 
priate secondary Abs. Proteins were detected and scanned with an Odyssey system (LI-COR Biosciences, Lincoln, NE, USA). Abs against RelA (sc-372X), p105/p50 (sc-7178X), p100/p52 (sc-298), RelB (sc-226X), c-Rel (sc-70), cyclin D1 (sc-20044), and Lamin A/C (sc-20681) were purchased from Santa Cruz Biotechnology. Abs against ERK1/2 (\#4695), p-ERK1/2 (\#4370S), ERCC1 (\#5437S), AKT (\#4691), p-AKT (Ser473, \#4060), p-AKT (Thr308, \#2965), BAD (\#9239), BIK (\#4592), BIM (\#2933), BID (\#2002), Bcl-xl (\#2764S), Mcl-1 (\#4572), PTEN (\#9559) and integrin $\beta$-1 (\#9699S) were obtained from Cell Signaling Technology. $\alpha$-tubulin (AJ1034a) and $\beta$-actin Abs (AO1215a) were purchased from Abgent. IRDye 680CW (926-32222) and IRDye 800CW secondary Abs (926-32210) were obtained from LI-COR Biosciences.

In-cell western assay. Cells were seeded in a 96-well flatbottom polystyrene plate. After culturing for $24 \mathrm{~h}$, medium was removed and the cells were fixed in phosphate-buffered saline (PBS) containing 3.7\% formaldehyde for $20 \mathrm{~min}$ at room temperature. The cells were washed three times with PBS containing $0.1 \%$ Triton X-100, and blocked in PBS containing $5 \%$ milk for $1.5 \mathrm{~h}$ at room temperature. The cells were then incubated with rabbit ERK1/2 or p-ERK1/2 Abs in the blocking buffer for $2 \mathrm{~h}$ at room temperature and subsequently washed with PBS containing 0.1\% Tween-20. Infrared antirabbit IRDye $800 \mathrm{CW}$ secondary Abs in the blocking buffer was then added and incubated for $1 \mathrm{~h}$ at room temperature in the dark. The plates were then imaged on an Odyssey infrared scanner using microplate 2 settings with sensitivity of 5.0 in the $800-n m$ wavelength channels. The fluorescence intensity was measured by Odyssey software and $\alpha$-tubulin expression was used as an internal control.

Real-time cell growth assay. Cell growth was performed with the xCELLigence RTCA instrument (Roche) using E-plate. In this assay, impedance for indicated times was continuously monitored by the system, and the value was indicated as 'Cell Index' which was determined by the number of cells seeded, the overall size and morphology of the cells, and the degree to which the cells interact with the sensor surface. The electrical impedance of each well was measured at regular intervals by the system. Data were collected and analyzed by RTCA software $1.2(20)$.

Cell cycle analysis. After washed in ice-cold PBS twice, cells were fixed with ice-cold $70 \%$ ethanol overnight at $4^{\circ} \mathrm{C}$. Fixed cells were centrifuged and counted. Cells $\left(1 \times 10^{6}\right)$ were then re-suspended in $2 \mathrm{ml}$ solution containing $40 \mu \mathrm{g} / \mathrm{ml}$ propidium iodide (PI; Sigma-Aldrich) and $100 \mu \mathrm{g} / \mathrm{ml}$ RNaseA (Invitrogen) for $30 \mathrm{~min}$ at $37^{\circ} \mathrm{C}$. Samples were analyzed by FACSCalibur $^{\mathrm{TM}}$ (BD Biosciences, Shanghai, China) within $1 \mathrm{~h}$ after preparation. After gating out cell debris and fixation of artifacts, flow cytometric analysis allowed for the discrimination of DNA contents.

$\mathrm{Ki}-67$ assay. Cells were cultured in RPMI-1640 media supplemented with $10 \%$ FBS on coverslides. After continuous culture for 24,48 and $72 \mathrm{~h}$, the slides were fixed in cold $4 \%$ paraformaldehyde for $30 \mathrm{~min}$, and treated with $1 \%$ Triton X-100 PBS solution for $10 \mathrm{~min}$. Then, 1X PBS with 10\% FBS was used to block the cells for $45 \mathrm{~min}$ at room temperature. Cells were incubated with a Ki-67 antibody (1:100 diluted; Santa Cruz Biotechnology, Santa Cruz, CA, USA). Following 1X PBS washing, sections were incubated for $30 \mathrm{~min}$ using the secondary Abs (rabbit anti-mouse IgA-B, GK500705; GTVision $^{\mathrm{TM}}$ III). Then, the 3,3-diaminobenzine (DAB) was used to visualize the immune-reactive products. Results were carried out by the system microscope IX71 (Olympus, Tokyo, Japan).

Terminal nucleotidyl transferase-mediated nick end labeling (TUNEL) assay. Cells were cultured on coverslides for 24, 48 and $72 \mathrm{~h}$ in a humidified incubator at $37^{\circ} \mathrm{C}$ and $5 \% \mathrm{CO}_{2}$. According to the manufacturer's instructions of TUNEL system kit (Roche), the slides were fixed by cold $4 \%$ paraformaldehyde for $30 \mathrm{~min}$. Following $1 \mathrm{X}$ PBS washing, $3 \% \mathrm{H}_{2} \mathrm{O}_{2}$ methanol solution was used to block the slides for $10 \mathrm{~min}$ at $20^{\circ} \mathrm{C}$. Then the slides were treated using the $1 \%$ Triton PBS solution for $2 \mathrm{~min}$ on ice after PBS washing. Avoiding light, $50 \mu \mathrm{l}$ of TUNEL reaction solution were applied to incubate the cells on slides for $60 \mathrm{~min}$ at $37^{\circ} \mathrm{C}$. Following PBS washing, the signals of TUNEL were converted using peroxidase (POD) for $30 \mathrm{~min}$ at $37^{\circ} \mathrm{C}$, and the sections were treated with DAB for $3 \mathrm{~min}$ at room temperature. Results were examined by the light system microscope IX71.

Cell migration assay. Cell migration was also performed with the xCELLigence RTCA instrument according to a previous report (20). In this assay, CIM-plate assembled with upper chamber and lower chamber was used. RPMI-1640 media (180 $\mu \mathrm{l}$ ) supplemented with 10\% FBS was added in each well on the lower chamber. Cells were suspended in RPMI-1640 media free of FBS, 10,000 cells/well were added on the upper chamber. After attachment, cell migration towards lower chamber containing $10 \%$ FBS media was continuously monitored by the system, and data were collected and analyzed by RTCA software 1.2.

Scratch healing assay. The confluent cell layers were scratched with a line using a sterile pipette tip of $200 \mu \mathrm{l}$ and washed three times with PBS. The scratched area was then imaged continuously at magnifications of x10 with the light system microscope IX71. The migratory distance is used to measure the migratory ability of cells.

Cell invasion assay. Cell invasion was also performed with the xCELLigence RTCA instrument. In this assay, CIM-plate with an upper chamber and a lower chamber was used. RPMI-1640 (180 $\mu \mathrm{l}$ ) supplemented with $10 \%$ FBS was added in each well in the lower chamber. Cells were suspended in RPMI-1640 free of FBS, 10,000 cells/well were added on the upper chamber. For cell invasion assay, wells of the upper chamber were precoated with Matrigel (cat. no. 356234; BD Bioscience) for at least $4 \mathrm{~h}$. After attachment, cells invaded through Matrigel towards the lower chamber containing 10\% FBS media were continuously monitored by the system, and data were collected and analyzed by RTCA software 1.2.

Gelatinase zymography. Gelatinase zymography was performed in an $8 \%$ SDS-PAGE gel in the presence of $0.1 \%$ 


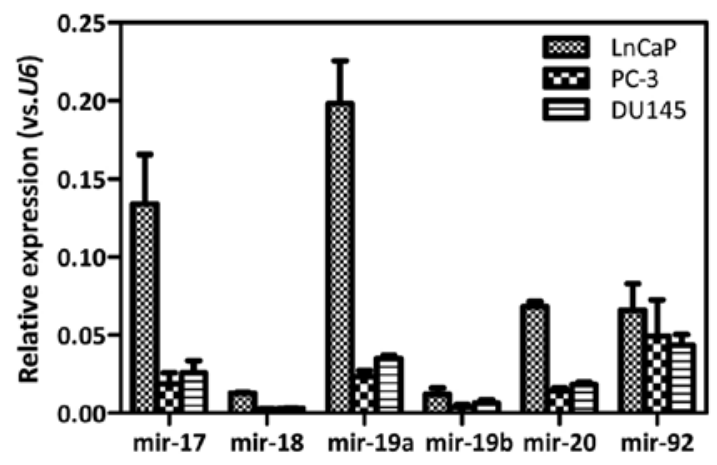

Figure 1. qRT-PCR analysis for expression of the six miR-17-92 family members in LnCaP, PC-3 and DU145 prostate cancer cell lines. U6 normalized gene expression, measured in triplicates, is displayed.

gelatin under non-reducing conditions. Culture media were mixed with sample buffer and loaded for SDS-PAGE with Tris-glycine SDS buffer. Samples were not boiled before electrophoresis. Following electrophoresis, the gels were washed twice in $2.5 \%$ Triton $\mathrm{X}-100$ for $30 \mathrm{~min}$ at room temperature to remove SDS. The gels were then incubated at $37^{\circ} \mathrm{C}$ overnight in substrate buffer containing $50 \mathrm{mM}$ Tris- $\mathrm{HCl}$ and $10 \mathrm{mM}$
$\mathrm{CaCl}_{2}$ at $\mathrm{pH} 8.0$ and stained with $0.5 \%$ Coomassie blue $\mathrm{R} 250$ in 50\% methanol and $10 \%$ glacial acetic acid for $30 \mathrm{~min}$ and destained. Upon renaturation of the enzyme, the gelatinases digested the gelatin in the gel to produce clear bands against an intensely stained background.

Statistical analysis. Data were expressed as mean \pm SD. Differences were analyzed by the Student's t-test. Sample sizes were chosen to produce statistically unambiguous results. A P-value of $\leq 0.05$ was considered significant, a P-value of $\leq 0.01$ and $\leq 0.001$, respectively, was considered as highly significant.

\section{Results}

Distinct miR-17-92 expression pattern in prostate cancer cell lines. The expression of the miR-17-92 cluster was determined in androgen-dependent $\mathrm{LnCaP}$ and androgen-independent DU145 as well as PC-3 prostate cancer cell lines by qRT-PCR analysis. The expression levels of individual miR-17-92 members in DU145 cells were comparable to that in PC-3 cells. The expression of $m i R-17(\mathrm{P}=0.0006), m i R-18$ $(\mathrm{P}<0.0001), m i R-19 a(\mathrm{P}=0.0005), m i R-19 b(\mathrm{P}=0.0575)$, and $m i R-20(\mathrm{P}<0.0001)$ was increased $\sim 3$ - to 6 -fold in $\mathrm{LnCaP}$ cells, as compared with that of DU145 cells. Similarly, the

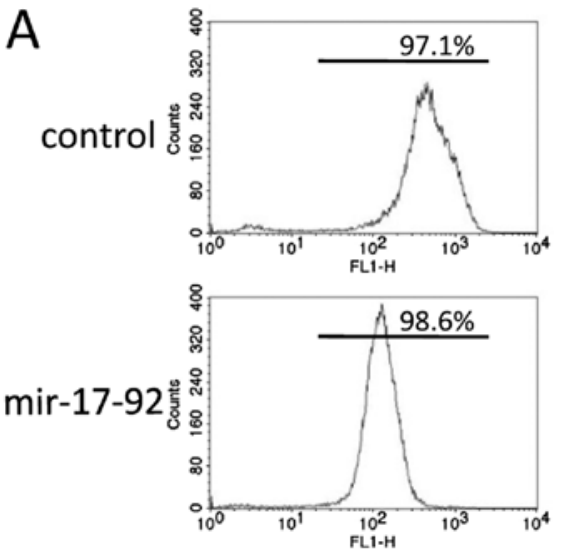

C

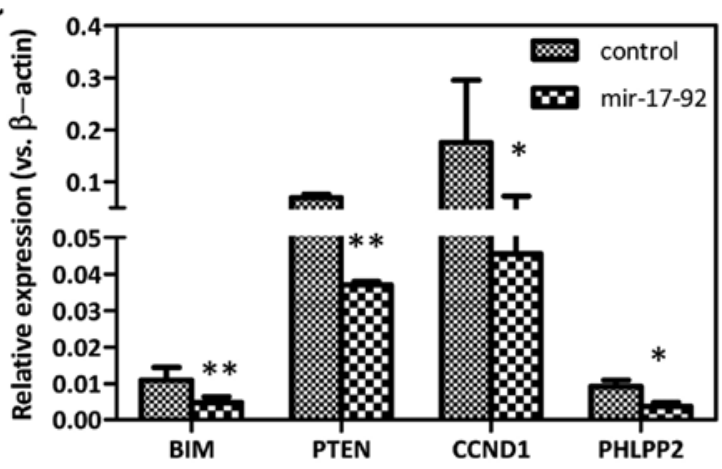

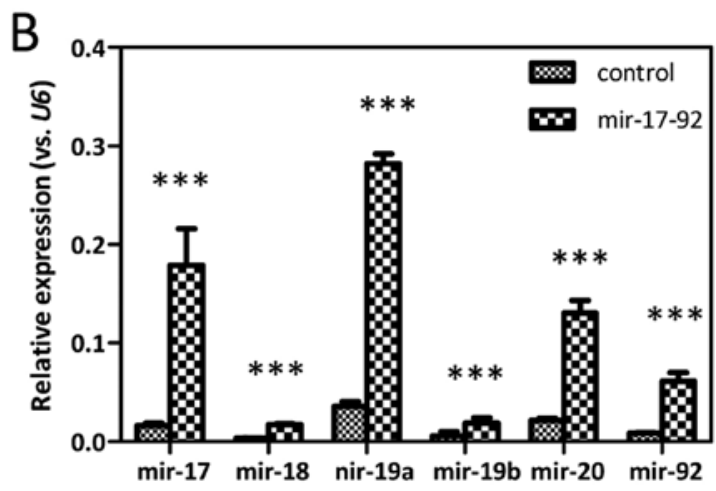
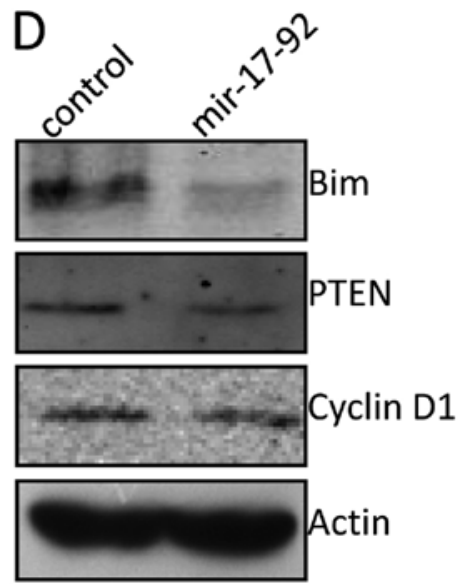

Figure 2. Establishing a miR-17-92-overexpressing DU145 cell line. (A) The GFP signals of the DU145-control and DU145-miR-17-92 cell lines were examined by flow cytometry. (B) The expression of the individual miR-17-92 family members between the two established cell lines was analyzed by qRT-PCR. U6 normalized gene expression, measured in triplicates is displayed. Significant differences are indicated (Student's t-test, $\left.{ }^{*} \mathrm{P}<0.05 ;{ }^{* * *} \mathrm{P}<0.01,{ }^{* * * *} \mathrm{P}<0.001\right)$. (C) mRNA levels of target genes of the miR-17-92 cluster were determined by qRT-PCR. $\beta$-actin normalized gene expression, measured in triplicates, is displayed. Significant differences are indicated (Student's t-test, ${ }^{*} \mathrm{P}<0.05,{ }^{* *} \mathrm{P}<0.01$ ). (D) Protein levels of target genes of the miR-17-92 cluster were determined by western blot analysis. The level of each protein was normalized against actin. 


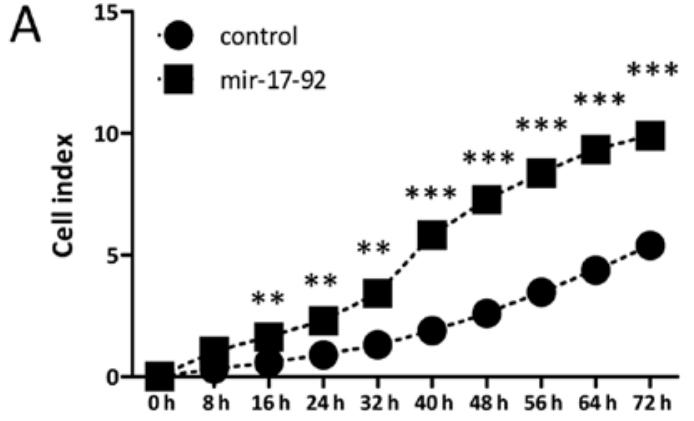

B

\begin{tabular}{c|ccc}
\hline & G0-G1 (\%) & S (\%) & G2-M (\%) \\
\hline control & $70.07 \pm 7.22$ & $18.97 \pm 3.66$ & $11.06 \pm 3.92$ \\
\hline mir-17-92 & $64.11 \pm 4.26$ & $21.36 \pm 1.78$ & $14.39 \pm 3.59$ \\
\hline
\end{tabular}
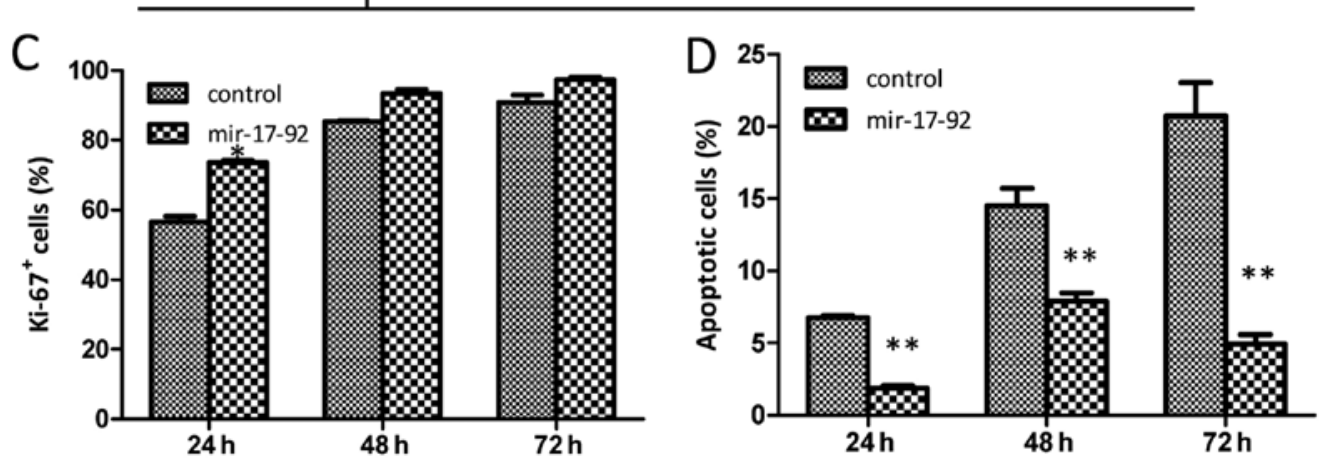

Figure 3. Overexpression of the miR-17-92 cluster promotes DU145 cell growth. (A) The cell growth curves between the DU145-control and DU145-miR-17-92 cells were detected by xCELLigence system using E-plate. Each plate was inoculated with 8,000 cells, and the cell growth was detected during a 72-h continuous monitoring. (Student's t-test, ${ }^{*} \mathrm{P}<0.05,{ }^{* *} \mathrm{P}<0.01,{ }^{* * * *} \mathrm{P}<0.001$ ). (B) The cell cycle analysis between the two established cell lines was examined by flow cytometry. The table presents the data of three phases $\left(\mathrm{G}_{0}-\mathrm{G}_{1}, \mathrm{~S}\right.$ and $\left.\mathrm{G}_{2}-\mathrm{M}\right)$. (C) The Ki-67 assay was carried out to quantitatively evaluate the proliferation capabilities. The bar chart represents the frequencies of Ki-67 positive cells of the two established cell lines. Significant differences are indicated (Student's t-test, ${ }^{\prime} \mathrm{P}<0.05,{ }^{* *} \mathrm{P}<0.01$ ). (D) The TUNEL assay was carried out to quantitatively evaluate the apoptotic cells. The bar chart represents the percentages of apoptotic cells of the two established cell lines. Significant differences are indicated (Student's t-test, ${ }^{*} \mathrm{P}<0.05,{ }^{* * *} \mathrm{P}<0.01$ ).

expression of $m i R-17(\mathrm{P}=0.004), m i R-18(\mathrm{P}<0.0001), m i R-19 a$ $(\mathrm{P}=0.0004)$, $m i R-19 b(\mathrm{P}=0.0121)$, and $m i R-20(\mathrm{P}<0.0001)$ was increased $\sim 4$ - to 8-fold in LnCaP cells, as compared with that of PC-3 cells. However, no significant difference in the miR-92 expression was detected among these three cell lines (Fig. 1). Therefore, the expression of the miR-17-92 cluster was much more abundant in androgen-dependent $\mathrm{LnCaP}$ cells than that in androgen-independent cells. The expression levels of the miR-17-92 cluster were near equivalent between the androgen-independent DU145 and PC-3 prostate cancer cells.

Introduction of the miR-17-92 cluster into prostate cancer cells. To understand the functions of miR-17-92 on the biological behavior of DU145 prostate cancer cells, plasmid overexpressing the miR-17-92 cluster was constructed and transfected into DU145 cells. The individual monoclones were subsequently selected by puromycin for two weeks. The percentages of GFP-positive cells in the established DU145-control and DU145-miR-17-92 cell lines were 97.1 and $98.6 \%$, respectively, detected by flow cytometry (Fig. 2A). The selected monoclone was further expanded and examined for the miR-17-92 expression by qRT-PCR analysis. The expression of every $m i R-17-92$ family member was markedly increased in the DU145-miR-17-92 cells compared to that in DU145-control cells, 11-fold for $m i R-17$ ( $\mathrm{P}<0.0001)$, 5-fold for miR-18 ( $\mathrm{P}<0.0001), 8$-fold for $m i R-19 a(\mathrm{P}<0.0001), 3$-fold for $m i R-19 b(\mathrm{P}=0.0096), 6$-fold for $m i R-20(\mathrm{P}=0.0001)$, and 7-fold for miR-92 $(\mathrm{P}<0.0001)$, indicating a successful introduction of the miR-17-92 cluster (Fig. 2B). The expression of some wellknown target genes of the miR-17-92 cluster, such as BIM, PTEN, CCND1 and PHLPP2 was evidently reduced in the DU145-miR-17-92 cells compared to that of DU145-control cells, albeit with different levels (Fig. 2C). In line with the qRT-PCR results, the expression of BIM, PTEN and cyclin D1 was reduced at the protein level detected by the western blotting (Fig. 2D). Therefore, it is shown that the DU145 prostate cancer cell line overexpressing the $m i R-17-92$ cluster was established successfully.

miR-17-92 overexpression promotes DU145 cell growth. The cell growth affected by the miR-17-92 overexpression was monitored dynamically using a real-time xCELLigence system. The cell growth of DU145 cells overexpressing $m i R-17-92$ was much faster than that of the DU145-control cells and statistically significant difference were found between the two established cell lines during the 72-h continuous monitoring (Fig. 3A). 

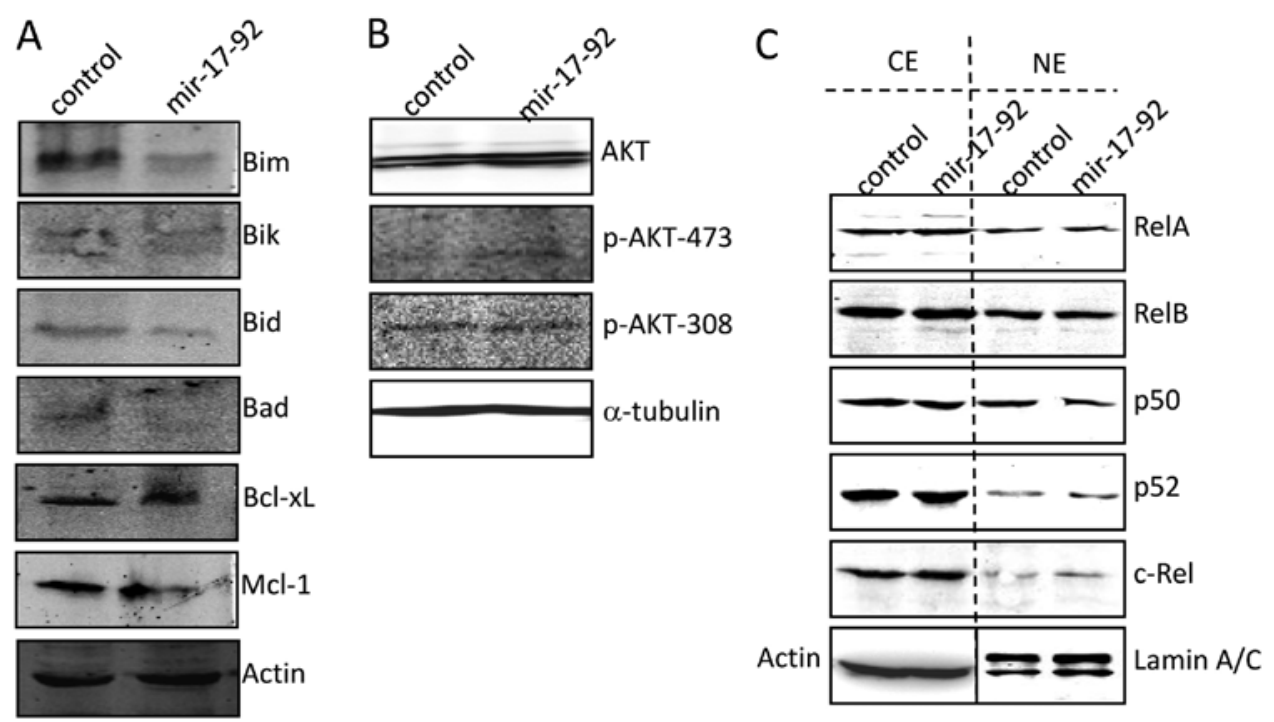

Figure 4. miR-17-92 overexpression regulates apoptosis-related and proliferation-related protein. (A) The expression of pro-apoptotic and anti-apoptotic genes at the protein level were analyzed by western blotting. The level of each protein was normalized against actin. (B) The protein expression level of AKT, p-AKT (Ser 473), and p-AKT (Thr 308) were analyzed by western blotting. (C) The protein expression of NF-kB subunits were analyzed by western blotting. Protein expression in cytoplasmic (CE) and nuclear portion (NE) was normalized against actin and LaminA/C, respectively.

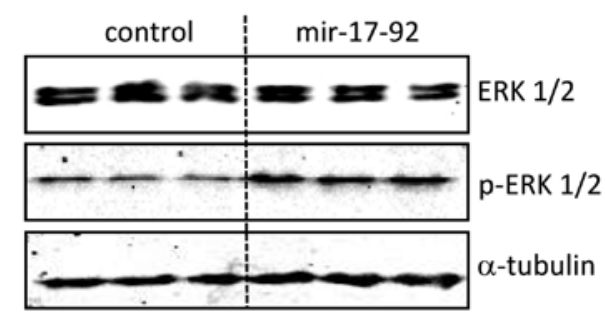

Figure 5. ERK1/2 and p-ERK1/2 expression in DU145-control and DU145-miR-17-92 cells. Western blot analysis for total ERK1/2 and p-ERK1/2 protein expression. $\alpha$-tubulin normalized protein expression was calculated in triplicates.

The cell cycle analysis and cellular DNA content measurement were detected by flow cytometry, and no obvious differences were found between the DU145-control and DU145-miR-17-92 cells in any of the three phases $\left(\mathrm{G}_{0}-\mathrm{G}_{1}, \mathrm{~S}\right.$ and $\left.\mathrm{G}_{2}-\mathrm{M}\right)$ (Fig. 3B). To investigate whether the miR-17-92 overexpression affects the proliferation capability of the DU145 cells, a Ki-67 cell proliferation assay was carried out. The frequencies of Ki-67positive cells in the DU145-control group were 56.57 \pm 1.68 , $85.48 \pm 0.26$ and $90.85 \pm 2.08 \%$ at 24,48 and $72 \mathrm{~h}$, respectively; while those in the DU145-miR-17-92 group were 73.64 \pm 0.68 , $93.43 \pm 1.23$ and $97.36 \pm 0.86 \%$ (Fig. 3C). The cellular proliferation of the DU145-miR-17-92 cells was higher at all time-points although, a statistically significant difference in the frequency of Ki-67-positive cells between the two cell lines was only observed at $24 \mathrm{~h}$. A TUNEL assay was performed to quantitatively examine apoptotic cells. As showed in Fig. 3D, both the DU145-control and DU145-miR-17-92 cells underwent apoptosis in a time-dependent manner. The percentages of apoptotic cells in the DU145-control group were $6.76 \pm 0.09$, $14.51 \pm 0.86$ and $20.73 \pm 1.64 \%$ at 24,48 and $72 \mathrm{~h}$, respectively; while those in the DU145-miR-17-92 group were $1.86 \pm 0.15$, $7.90 \pm 0.40$ and $4.92 \pm 0.48 \%$. Apoptosis was markedly reduced in the DU145-miR-17-92 cells and there was a statistically significant difference in the frequencies of apoptotic cells at all time-points between the two cell lines. Thus, it is shown that $m i R-17-92$ overexpression promoted cell growth in DU145 prostate cancer cells. The diminished cellular apoptosis together with the increased cellular proliferation contributed together to the enhanced growth upon the introduction of the miR-17-92 cluster into DU145 cells.

miR-17-92 regulates apoptosis-related and proliferationrelated protein. As shown in Fig. 4A, the expression of pro-apoptotic proteins such as BIM, BIK, BID and BAD was distinctly reduced in the DU145-miR-17-92 cells compared to that of the DU145-control cells. However, no significant difference in anti-apoptotic proteins such as Bcl-xL and Mcl-1 were found between the two cell lines. The AKT signaling molecules were examined. The expression level of total AKT was comparable in the whole-cell extracts of the DU145-control and DU145-miR-17-92 cells. However, miR-17-92 overexpression induced clear phosphorylation of AKT at Ser 473, but not at Thr 308 (Fig. 4B), which was correlated with the inhibited PTEN expression (Fig. 2D). The expression of RelA and p50, contributing to the canonical NF- $\mathrm{kB}$ activity, was comparable between the DU145-miR-17-92 and DU145-control cells at both cytoplasmic and nuclear fractions. The expression of RelB and p52, contributing to the non-canonical NF- $\mathrm{kB}$ activity, also showed no difference between the two cell lines (Fig. 4C). Therefore, the NF- $\mathrm{BB}$ signaling was not affected by $m i R-17-92$ overexpression in DU145 cells. Collectively, forced introduction of the miR-17-92 cluster into DU145 cells suppressed the expression of pro-apoptotic related protein, particularly BIM, which functioned critically in apoptosis resistance. Moreover, forced introduction of the miR-17-92 cluster into DU145 cells activated the AKT signaling due to PTEN inhibition, which contributed at least partially to the increased cellular proliferation. 

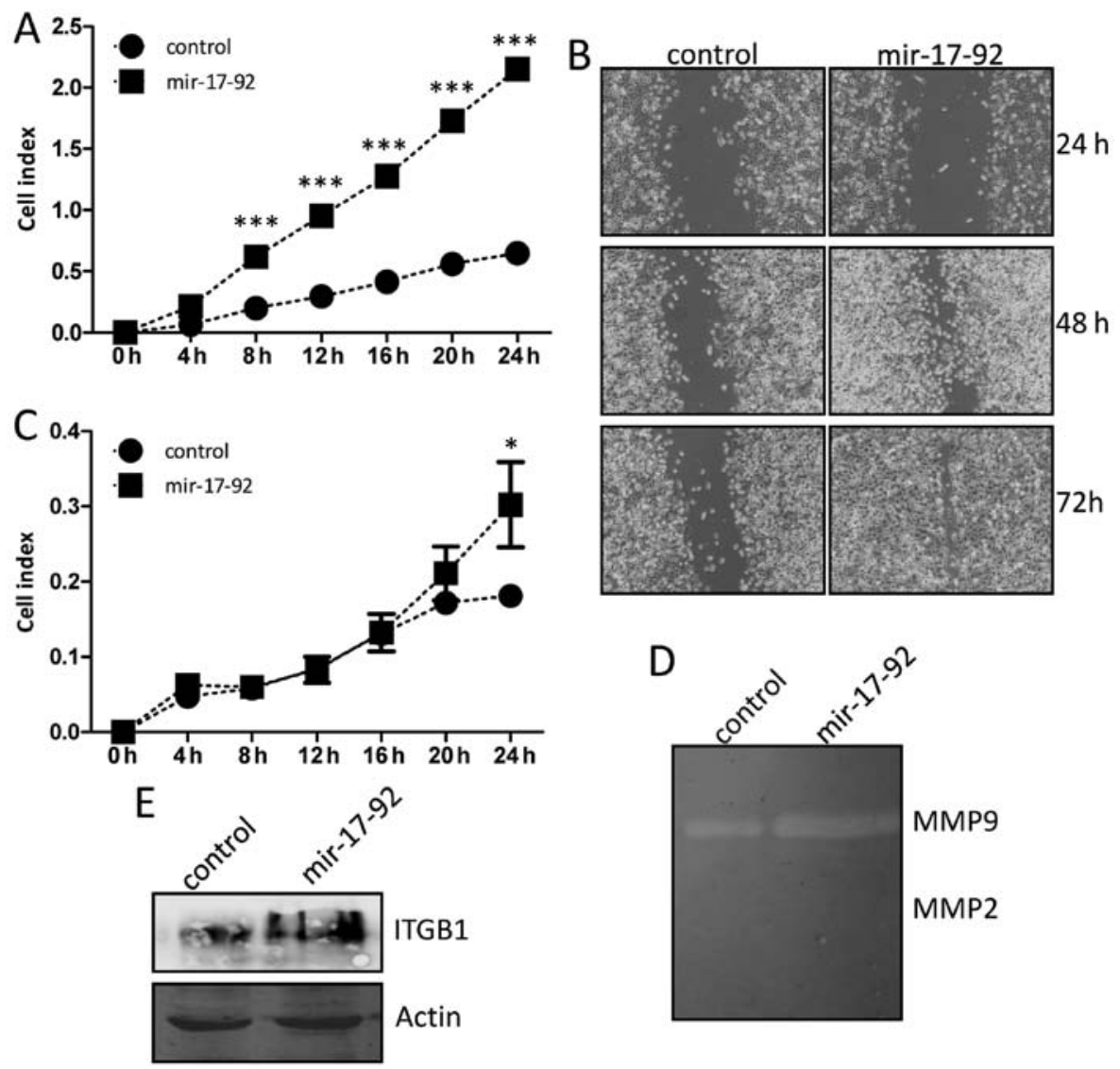

Figure 6. miR-17-92 overexpression promotes the migration and invasion ability of DU145 cells. (A) The migration ability of DU145-control and DU145-miR-17-92 cells was detected by a real-time xCELLigence system using CIM-plates. Each plate was inoculated with 10,000 cells, and the migration was detected via 24-h monitoring. (B) The migration ability of cells was detected by the scratch healing assay at 24,48 and $72 \mathrm{~h}$. (C) The invasion of the two established cell lines was detected by a real-time xCELLigence system using matrigel (1:40 dilution)-coated CIM-plates. Each plate was inoculated with 10,000 cells, and the invasion ability was detected via 24-h monitoring. (D) Activity of MMP-2 and MMP-9 was evaluated by the gelatin zymography experiment. (E) The protein expression of integrin $\beta-1$ was analyzed by western blotting in the two established cell lines. The level of each protein was normalized against actin.

miR-17-92 overexpression induces ERK1/2 phosphoration in DU145 cells. The protein expression level of total ERK1/2 was comparable between the DU145-miR-17-92 and DU145-control cells. However, miR-17-92 overexpression in DU145 cells induced continuous phosphorylation of ERK1/2 (p-ERK1/2) detected by western blot analysis (Fig. 5). In addition, the expression of total ERK1/2 and p-ERK1/2 was analyzed quantitatively in situ by an In-Cell western assay (data not shown). The ERK1/2 expression in the DU145-miR-17-92 cells was similar to that of the DU145-control cells. In line with the results from western blot analysis, the expression of p-ERK1/2 was increased $\sim 3$-fold $(\mathrm{P}<0.0001)$ in the DU145-miR-17-92 cells as compared to that in the DU145-control cells (data not shown). Therefore, overexpression of the miR-17-92 cluster in DU145 prostate cancer cells induces the phosphorylation of ERK1/2 without affecting basal ERK1/2.

miR-17-92 overexpression enhances migration and invasion abilities of DU145 cells. The migration ability was examined dynamically by a real-time xCELLigence system using CIM-plates. The DU145 cells overexpressing miR-17-92 migrated markedly faster than that of the DU145-control cells during the 24-h continuous monitoring, and there were significantly statistical difference in the migration assay between the two established cell lines (Fig. 6A). The in vitro scratch assay was also carried out to evaluate quantitatively the migration ability of cells. A scratched cell monolayer was generated in both cell lines and images were captured after culturing for 24, 48 and $72 \mathrm{~h}$. At the 48 and 72-h time-point of the assay, it was shown that the DU145-miR-17-92 cells migrated from the edge towards the center of the scratch more rapidly than that of the DU145-control cells (Fig. 6B), indicating better migratory ability. The invasion ability was also examined by the real-time xCELLigence system using matrigel (dilution at 1:40)-coated CIM-plates. The DU145 cells overexpressing miR-17-92 invaded through matrigel faster than that of the DU145-control cells at the $24 \mathrm{~h}$ time-point, and there was statistically significant difference between the two established cell lines (Fig. 6C). The gelatin zymography experiment was further performed to explore the relative amounts of active and inactive gelatinase (MMP-2 or MMP-9). As showed in Fig. 6D, the MMP-2 activity was not detected in either of the cell lines, and the MMP-9 activity was slightly increased in the DU145-miR-17-92 cells compared to that of the DU145control cells, indicating the enhanced invasion ability of cells. Notably, integrin $\beta-1$ expression at the protein level was clearly induced in the DU145-miR-17-92 cells compared to that of the DU145-control cells (Fig. 6E). Thus, these results indicated 

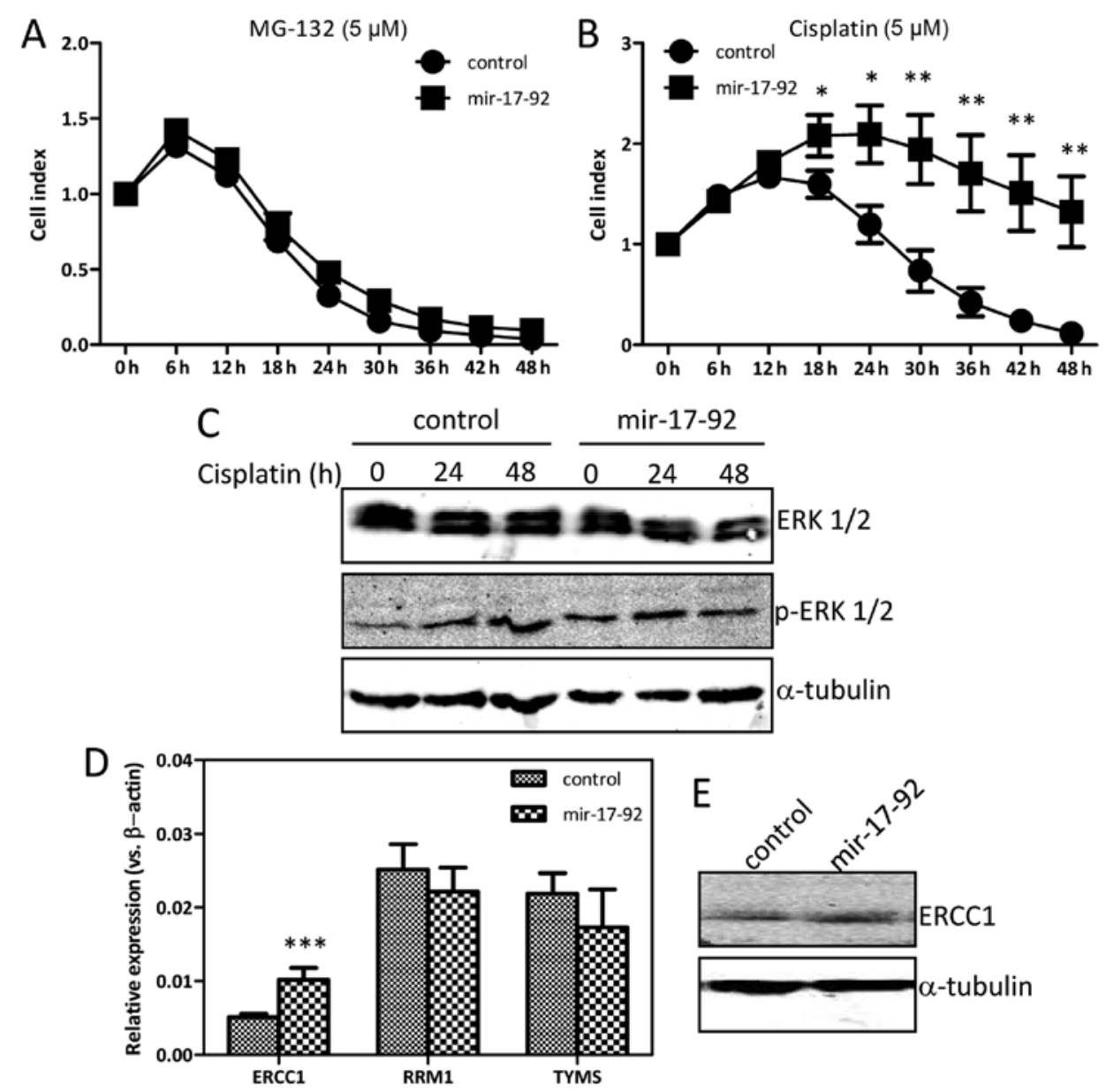

Figure 7. miR-17-92 overexpression modulated sensitivity to cisplatin of DU145 cells. DU145-control and DU145-miR-17-92 cells were seeded in E-plate and continuously monitored by the xCELLigence system. Cells were treated with (A) MG-132 $(1 \mu \mathrm{M})$ or (B) cisplatin $(5 \mu \mathrm{M})$. Cell index for each cell type measured in triplicates, is displayed. Significant differences are indicated (Student's t-test, ${ }^{*} \mathrm{P}<0.05 ;{ }^{* *} \mathrm{P}<0.01$ ). (C) The protein expression of ERK1/2 and p-ERK1/ in DU145-control and DU145-miR-17-92 cells treated with cisplatin. (D) The mRNA expression of ERCC1, RRM1 and TYMS in the two cell lines. $\beta$-actin normalized protein expression was calculated in triplicates. Significant differences are indicated (Student's t-test, $\left.{ }^{*} \mathrm{P}<0.05 ;{ }^{* * *} \mathrm{P}<0.01,{ }^{* * *} \mathrm{P}<0.001\right)$. $(\mathrm{E})$ The protein expression of ERCC1 in the two cell lines. The level of each protein was normalized against $\alpha$-tublin.

that $m i R-17-92$ overexpression promoted the migration and invasion of DU145 prostate cancer cells, and the upregulated integrin $\beta-1$ was implicated in these processes.

miR-17-92 overexpression affects cisplatin-sensitivity. The effects of MG-132 and cisplatin on the DU145-miR-17-92 and the DU145-control cells were monitored dynamically by the xCELLigence system.MG-132, a proteasome inhibitor, caused considerable cell death in both cell lines in a time-dependent manner (Fig. 7A). The cisplatin-treatment led to significant cell death in DU145-control cells in a time-dependent manner (Fig. 7B). Interestingly, the DU145-miR-17-92 cells were relatively resistant to the cisplatin-treatment as compared with the DU145-control cells at the time-point of $18 \mathrm{~h}(\mathrm{P}=0.0272)$, $24 \mathrm{~h}(\mathrm{P}=0.0105), 30 \mathrm{~h}(\mathrm{P}=0.0064), 36 \mathrm{~h}(\mathrm{P}=0.0054), 42 \mathrm{~h}$ $(\mathrm{P}=0.0047)$ and $48 \mathrm{~h}(\mathrm{P}=0.0044)$. Overexpressing the miR-17-92 cluster in DU145 cells increased $\mathrm{IC}_{50}$ of cisplatin from 3.45 to $5.88 \mu \mathrm{M}$. During cisplatin-treatment, the protein level of basal ERK1/2 remained high and unchanged in both cell lines (Fig. 7C). The expression level of p-ERK1/2 was increased gradually in a time-dependent manner in the DU145-control cells upon cisplatin-treatment. However, the expression of p-ERK1/2 in the DU145-miR-17-92 cells, which was already at a high level in the untreated condition, was not influenced and remained high upon cisplatin-treatment. The mRNA level of ERCCl, RRMI and TYMS was analyzed by qRT-PCR. As shown in Fig. 7D, the ERCCl mRNA level was increased $\sim 2$-fold ( $\mathrm{P}=0.0001)$ in DU145-miR-17-92 cells as compared to that in DU145-control cells, while the RRMI and TYMS mRNA levels were similar in the two cell lines. The expression of ERCC1 was also increased at the protein level in the DU145-miR-17-92 cells as compared to that in the DU145-control cells (Fig. 7E). Collectively, overexpression of the miR-17-92 cluster in DU145 prostate cancer cells caused chemo-resistance to cisplatin, at least partially due to the sustained and high level of ERK1/2 phosphoration. In addition, the continuously activated AKT signaling together with upregulated ERCC1 also contributed to development of cisplatin-resistance.

\section{Discussion}

In the present study, the miR-17-92 cluster regulation of diverse cellular behavior of prostate cancer cells was systematically examined. The expression levels of the miR-17-92 cluster in the androgen-independent cells were much lower 
than that in the androgen-dependent prostate cancer cells. Forced expression of the miR-17-92 cluster into the DU145 androgen-independent cells interfered with multiple biological events. The stimulatory function of the $m i R-17-92$ cluster in prostate cancer cell growth, migration, invasion and acquired cisplatin-resistance were clearly evident in vitro.

The $m i R-17-92$ cluster is widely expressed in different cell types and essential for many developmental and pathogenic processes. The expression of individual members of the $m i R-17-92$ cluster in the three prostate cancer cell lines was analyzed by qRT-PCR. In line with a previous report (16), we found that the expression pattern of the $m i R-17-92$ cluster was clearly different between the androgen-dependent and androgen-independent prostate cancer cell lines. The expression levels of $m i R-17, m i R-18, m i R-20$ and $m i R-19$ in the androgen-dependent $\mathrm{LnCaP}$ cells were much higher than that in the androgen-independent DU145 and PC-3 cells. However, the expression pattern of the two androgen-independent prostate cancer cell lines, DU145 and PC-3, was quite similar according to the present study, albeit with varied levels. Therefore, the expression of the miR-17-92 cluster was negatively correlated with the AR expression status in prostate cancer cell lines, suggesting that the miR-17-92 cluster is possibly involved in the progression from androgen-dependent into androgen-independent stage due to certain, yet unknown, reasons.

To identify the contribution of the miR-17-92 cluster to tumorigenesis in prostate cancer, the $m i R-17-92$ cluster was successfully transfected into the androgen-independent DU145 cells, in which the miR-17-92 cluster was minimally expressed. The mRNA expression of a number of well-known targets including PTEN, BIM, CCND1 and PHLPP2 was inhibited in the miR-17-92-overexpressing DU145 cells. In the study, we observed significant enhancement of prostate cancer cell growth on the introduction of the $m i R-17-92$ cluster and found that the improved cellular proliferation together with the diminished apoptosis both contributed to the rapid cell growth.

Located in the third intron of the C13orf 25 gene, the $m i R-17-92$ cluster is regulated by transcription factors such as c-Myc, E2F family members, and STAT3, each of which are frequently activated in cancer. Previous evidence suggests that the growth stimulatory effect of the miR-17-92 cluster is partially attributable to the unbalance between cellular proliferation and apoptosis. Our findings here are similar with observations in a variety of hematopoietic and solid malignancies (21). Conditionally active the $m i R-17-92$ cluster in lymphocytes increases proliferation and reduces activationinduced cell death (22). Leukemia expressing increased levels of the miR-17-19 construct enhances cellular proliferation associated with reduced expression of the cyclin-dependent kinase inhibitor, $C D K N 1 / p 21$, which is a direct target of $m i R-17$ and a potent negative regulator of the G1-S checkpoint of cell cycle progression $(23,24)$. The $m i R-17-92$ cluster also conveys significant stimulatory activity in cell growth of lung and hepatocellular cancer cells in vitro $(25,26)$. Overexpression of the miR-17-92 cluster enhances cholangiocarcinoma growth in hairless outbred mice (27). Gain- and loss-of-function assays demonstrate that miR-17 affects the proliferation of gastric cancer cells both in vitro and in vivo (28). Overexpression of miR-17 in gastric cancer cells is correlated with the amplification of several proliferation-associated oncogene such as
$M Y C, C C N E 1, E R B B 2$ and FGFR2. Knockdown of $m i R-17$ suppresses the proliferative potential of KATO-III gastric cancer cells, which is coupled with markedly decreased phosphorylated ERK1/2 levels (29). In fact, a variety of cell proliferation-associated and apoptosis-associated genes such as $M A P K, E 2 F$ and $J A K, A K T, S T A T, B c l-2, X I A P, P I K 3 R 3$ are potentially targeted by the $m i R-17-92$ cluster in a tissue-specific manner (30). In the present study, we showed that the total AKT was not changed upon introduction of the miR-17-92 cluster into DU145 cells; however, the phosphorylated AKT (p-AKT) at Ser 473 was induced. Similarly, the induced phosphorylation of ERK1/2 (p-ERK1/2) was also observed, though the total ERK levels remained unchanged. Taken together, these data suggested that overexpession of the miR-17-92 cluster in DU145 prostate cancer cells increased cellular proliferation, the activated AKT and ERK1/2 signaling pathways were implicated in the process.

Many studies have also reported oncogenic activity of the miR-17-92 cluster through suppression of apoptotic genes. In non-small cell lung cancer cells, prostaglandin E2 upregulates the MYC gene followed by elevation of the miR-17-92 expression, which reduces PTEN expression and enhances apoptosis resistance (31). Antisense-mediated inhibition of $m i R-17$ and $m i R-20$ induces clear apoptosis in the $m i R-17-92$-overexpressing lung cancer cells, which is partially related to the induction of E2F1 (32). Suppression of $m i R-17$ in thyroid cancer cells leads to complete cell growth arrest, presumably due to caspase activation resulting in apoptosis (33). The highlevel amplification of the miR-17-92 in glioblastoma inhibits apoptosis by targeting CDKN1A, E2F1, PTEN and CTGF (34). The survival effect of $m i R-19$ is mostly mediated by the increased PI3K/AKT signaling, largely due to the posttranscriptional repression of PTEN $(35,36)$. miR-92 levels in colon cancer cells have been shown to correlate negatively with reduced apoptosis and with BIM expression (12). A potential anti-apoptotic role for $m i R-20$ has been found in PC-3 prostate cancer cell line (17). In the present study, we observed that overexpressing of the miR-17-92 cluster in DU145 cells led to clear reduction of apoptosis, which was coupled with the suppressed expression of certain pro-apoptotic proteins such as BIM, whose dysregulation affects apoptosis in diverse cancer cells. BIM is a direct target of multiple members of the $m i R-17-92$ cluster and other related miRNAs. As a proapoptotic protein, BIM regulates cell death in various settings through its ability to antagonize anti-apoptotic protein such as Bcl-2 (37). Inhibited PTEN expression also contributed to the apoptotic resistance. PTEN is a crucial negative regulator of the highly oncogenic pro-survival PI3K/AKT signaling pathway, and is predominantly targeted by $m i R-19$. In response to a variety of extracellular signals, the PI3K/AKT pathway elicits diverse cellular responses to promote cell survival, rapid proliferation and cell growth. Other molecular events regulating the balance of the cellular proliferation and apoptosis such as the NF- $\mathrm{NB}$ signaling, which is regulated by the $m i R-17-92$ cluster $(38,39)$, were not affected in the prostate cancer cells according to the present study. Thus, we presented evidence that overexpession of the $m i R-17-92$ cluster in DU145 prostate cancer cells promoted cell growth, the activated AKT and ERK1/2 signaling, and dysregulated expression of apoptosis-related protein played important roles. It is also 
conceivable that additional pathways regulated by $m i R-17-92$ cluster could synergize together to promote cell growth. The $m i R-17-92$ cluster is indeed a key component of the complex regulatory signaling network for cellular proliferation and apoptosis in prostate cancer cells.

Furthermore, we showed that overexpression of the $m i R-17-92$ cluster substantially enhanced the migration and invasion of DU145 prostate cancer cells. Our findings are in line with previous reports that the $m i R-17-92$ cluster plays a role in cancer invasion and metastasis $(26,40)$. Overexpression of $m i R-17$ in MCF-7 breast cancer cells renders the ability of invasiveness and migration by targeting the HBP1/ $\beta$-catenin pathway. Downregulation of endogenous $m i R-17$ in MDA-MB231 cells suppresses the migration and invasion (41). In addition, $m i R-17$ can enhance the migration ability of melanoma cells by inhibiting the translation of ETV1 (42). $m i R-19$ facilitates gastric cancer cell migration and invasion through targeting the antagonist of c-myc-MXD1 (43). In contrast, forced expression of $m i R-92$ suppresses peritoneal dissemination of ovarian cancer in vivo by inhibiting integrin $\alpha-5$ expression (44). For the first time, we provided evidence that the $m i R-17-92$ cluster played a positive role in regulating the migration and invasion of prostate cancer cells, and therefore functioned as an oncogene in prostate cancer cells.

Diverse molecular regulators, including adhesion receptor families, receptor tyrosine kinase, cytoskeleton protein, adapters and signaling molecules, are involved in the regulation of migration and invasion of cancer cells. Interestingly, we found that the expression of integrin $\beta-1$ was upregulated in the DU145-miR-17-92 cells. Integrin $\beta$-1, encoded by the ITGB1 gene, belongs to the family of heterodimeric transmembrane cell surface receptors that contain $18 \alpha$ and $8 \beta$ subunits and bridge crosstalk between cell-cell and cell-extracellular matrix (ECM). Integrin $\beta-1$ activation is a key regulator in the switch from cellular dormancy to metastatic growth in vitro and in vivo. Overexpression of integrin $\beta-1$ has been found in various epithelial malignancies during invasion, angiogenesis and metastasis. In some human solid tumors, increased expression of integrin $\beta-1$ correlates with enhanced metastatic potential and shortened patient survival $(45,46)$. Integrin $\beta-1$ and integrin-induced autophosphorylation of focal adhesion kinase (FAK) are increased in prostate cancer cells in primary prostate cancer and lymph node metastases. Increased integrin $\beta-1$ activation in prostate cancer cells correlates with metastatic potential in vivo. Using the integrin $\beta-1$ neutralizing $\mathrm{mAbs}$ 33B6 inhibits the phosphorylation of integrin $\beta-1$ downstream effectors, FAK and AKT, leading to increased apoptosis (47). The activation of integrin $\beta-1$ is likely through an inside-out mechanism, which induces conformational changes of integrin $\beta-1$ in the absence of ECM ligands. Diverse mechanisms contribute to the inside-out activation, including interaction with its regulatory molecules, biochemical modification of the integrins, and regulation by extracellular growth factors. Activation of integrin $\beta-1$ could also be regulated by the PI3K/AKT signaling pathway (48). Further studies on the mechanisms by which integrin $\beta-1$ become constitutively activated upon introduction of the miR-17-92 cluster into the prostate cancer cells are warranted.

Besides its role in tumor onset and progression, the miR-17-92 cluster can enhance chemo-resistance. In the present study, we have also illustrated that overexpression of the miR-17-92 cluster caused severe chemo-resistance to cisplatin. Treated with cisplatin, DU145-miR-17-92 cells had less cell death and a much higher $\mathrm{IC}_{50}$ value than that of DU145-control cells. Cisplatin exerts its anticancer effects by disrupting DNA structure in cell nuclei through the formation of intra-strand and inter-strand cross-links. Cisplatin-based chemotherapy has been widely used to treat a variety of cancers, but dose limiting toxicities or intrinsic and acquired resistance often reduced its clinical benefit in several types of cancer including prostate cancer $(49,50)$. Many mechanisms are involved in developing cisplatin resistance such as change in the expression levels of certain miRNAs, cytoplasmic translocation of $\mathrm{p} 21$ by phosphorylation, and activation of the PI3K/AKT signaling pathway. Among those, the PI3K/AKT signaling pathway plays a specific role (51). Nevertheless, the involvement of the miR-17-92 cluster in developing cisplatinresistance is still contradictory. For example, $m i R-17$ and $m i R-20$ are downregulated in cisplatin-resistant A549/DDP (cisplatin) cells compared with A549 non-small lung cancer cells by miRNA microarray profiling analysis. Inhibition of $m i R-17$ and $m i R-20$ increases cisplatin-resistance while overexpression of $m i R-17$ and $m i R-20$ decreases cisplatin-resistance in A549 cells (52). In the present study, overexpression of the miR-17-92 cluster activated the AKT signaling pathway due to inhibition of PTEN, which could in part explain the development of cisplatin-resistance in DU145 cells.

ERK1/2 signaling pathway is shown to be associated with various cellular processes such as differentiation, proliferation, transformation and apoptosis. Anti-proliferative and apoptotic effects of cisplatin have been attributed to activation of ERK1/2 signaling in various cell lines. Cisplatin treatment results in dose- and time-dependent activation of ERK1/2, which is important for the induction of cisplatin-induced apoptosis in HeLa and A549 cells (53). Cisplatin-induced ERK1/2 activation is an upstream regulator of $\mathrm{p53}$, which leads to DNA damage caused by cisplatin (54). In the present study, cisplatin-treatment induced the phosphorylaion of ERK $1 / 2$ in a time-depend manner while the total ERK levels remained high and unchanged in DU145 control cells, correlated with the time-dependent apoptosis. Interestingly, the phosphorylaion of ERK1/2 was constantly high during the cisplatin-treatment in DU145-miR-17-92 cells, suggesting that the continuously activated ERK signaling also contributed to cisplatin resistance.

High ERCC1 expression in cancer cells is associated with lower cisplatin sensitivity and is a potential indicator of response to cisplatin and prognosis $(55,56)$. Accumulation of ERK1/2 phosphorylation can increase ERCC1 expression to protect hepatoma and melanoma cells from DNA damage $(57,58)$. siRNA-mediated silencing of ERCC1 increases the cisplatin sensitivity in PC-3 and DU145 prostate cancer cell lines (59). In DU145 prostate cancer cells, overexpressing the $m i R-17-92$ cluster caused upregulated ERCC1 expression, which was also responsible for the acquired cisplatin-resistance. The expression level of the miR-17-92 cluster in prostate cancer cells could be considered as a potential biomarker in platinumbased therapies.

These findings here establish a key tumor-promoting role of the miR-17-92 cluster in the carcinogenesis of prostate cancer. The miR-17-92 cluster plays a crucial role in cell growth of 
the DU145 prostate cancer cells due to regulation of cellular proliferation and apoptosis. Given the potent effects on cell growth, migration, invasion, and chemo-sensitivity exerted by the $m i R-17-92$ cluster, miRNAs belonging to the cluster represent attractive targets for cancer therapy.

\section{Acknowledgements}

The present was supported by the National Natural Science Foundation of China (grant no. 81172433 to F.G.) and the Natural Science Foundation of Jiangsu Provincial (grant no. BK20151211 to F.G.).

\section{References}

1. Saini S, Majid S and Dahiya R: Diet, microRNAs and prostate cancer. Pharm Res 27: 1014-1026, 2010.

2. Porkka KP, Pfeiffer MJ, Waltering KK, Vessella RL, Tammela TL and Visakorpi T: MicroRNA expression profiling in prostate cancer. Cancer Res 67: 6130-6135, 2007.

3. Lu J, Getz G, Miska EA, Alvarez-Saavedra E, Lamb J, Peck D, Sweet-Cordero A, Ebert BL, Mak RH, Ferrando AA, et al: MicroRNA expression profiles classify human cancers. Nature 435: 834-838, 2005.

4. Sun T, Wang Q, Balk S, Brown M, Lee GS and Kantoff P: The role of microRNA-221 and microRNA-222 in androgen-independent prostate cancer cell lines. Cancer Res 69: 3356-3363, 2009.

5. He L, Thomson JM, Hemann MT, Hernando-Monge E, Mu D, Goodson S, Powers S, Cordon-Cardo C, Lowe SW, Hannon GJ, et al: A microRNA polycistron as a potential human oncogene. Nature 435: 828-833, 2005 .

6. Ota A, Tagawa H, Karnan S, Tsuzuki S, Karpas A, Kira S, Yoshida $\mathrm{Y}$ and Seto M: Identification and characterization of a novel gene, C13orf25, as a target for 13q31-q32 amplification in malignant lymphoma. Cancer Res 64: 3087-3095, 2004.

7. Volinia S, Calin GA, Liu CG, Ambs S, Cimmino A, Petrocca F Visone R, Iorio M, Roldo C, Ferracin M, et al: A microRNA expression signature of human solid tumors defines cancer gene targets. Proc Natl Acad Sci USA 103: 2257-2261, 2006.

8. Mogilyansky E and Rigoutsos I: The miR-17/92 cluster: A comprehensive update on its genomics, genetics, functions and increasingly important and numerous roles in health and disease. Cell Death Differ 20: 1603-1614, 2013.

9. Mu P, Han YC, Betel D, Yao E, Squatrito M, Ogrodowski P, de Stanchina E, D'Andrea A, Sander C and Ventura A: Genetic dissection of the miR-17 92 cluster of microRNAs in Myc-induced B-cell lymphomas. Genes Dev 23: 2806-2811, 2009.

10. van Haaften $\mathrm{G}$ and Agami R: Tumorigenicity of the miR-17-92 cluster distilled. Genes Dev 24: 1-4, 2010.

11. Conkrite K, Sundby M, Mukai S, Thomson JM, Mu D, Hammond SM and MacPherson D: miR-17-92 cooperates with RB pathway mutations to promote retinoblastoma. Genes Dev 25: 1734-1745, 2011.

12. Tsuchida A, Ohno S, Wu W, Borjigin N, Fujita K, Aoki T, Ueda S, Takanashi M and Kuroda M: miR-92 is a key oncogenic component of the miR-17-92 cluster in colon cancer. Cancer Sci 102: 2264-2271, 2011.

13. Osada H and Takahashi T: let-7 and miR-17-92: Small-sized major players in lung cancer development. Cancer Sci 102: 9-17, 2011.

14. Cho WC: OncomiRs: The discovery and progress of microRNAs in cancers. Mol Cancer 6: 60, 2007.

15. Pesta M, Klecka J, Kulda V, Topolcan O, Hora M, Eret V, Ludvikova M, Babjuk M, Novak K, Stolz J, et al: Importance of miR-20a expression in prostate cancer tissue. Anticancer Res 30: 3579-3583, 2010

16. Sikand K, Slane SD and Shukla GC: Intrinsic expression of host genes and intronic miRNAs in prostate carcinoma cells. Cancer Cell Int 9: 21, 2009.

17. Sylvestre Y, De Guire V, Querido E, Mukhopadhyay UK, Bourdeau V, Major F, Ferbeyre G and Chartrand P: An E2F/ miR-20a autoregulatory feedback loop. J Biol Chem 282: 2135-2143, 2007

18. Watahiki A, Wang Y, Morris J, Dennis K, O'Dwyer HM, Gleave M, Gout PW and Wang Y: MicroRNAs associated with metastatic prostate cancer. PLoS One 6: e24950, 2011.
19. Guo F, Kang S, Zhou P, Guo L, Ma L and Hou J: Maspin expression is regulated by the non-canonical NF- $\kappa \mathrm{B}$ subunit in androgen-insensitive prostate cancer cell lines. Mol Immunol 49: 8-17, 2011.

20. Liu F, Zhou J, Zhou P, Chen W and Guo F: The ubiquitin ligase CHIP inactivates NF- $\kappa$ B signaling and impairs the ability of migration and invasion in gastric cancer cells. Int $\mathrm{J}$ Oncol 46: 2096-2106, 2015

21. Olive $\mathrm{V}, \mathrm{Li} \mathrm{Q}$ and $\mathrm{He} \mathrm{L}$ : mir-17-92: A polycistronic oncomir with pleiotropic functions. Immunol Rev 253: 158-166, 2013.

22. Xiao C, Srinivasan L, Calado DP, Patterson HC, Zhang B, Wang J, Henderson JM, Kutok JL and Rajewsky K: Lymphoproliferative disease and autoimmunity in mice with increased miR-17-92 expression in lymphocytes. Nat Immunol 9: 405-414, 2008.

23. Wong P, Iwasaki M, Somervaille TC, Ficara F, Carico C, Arnold C, Chen CZ and Cleary ML: The miR-17-92 microRNA polycistron regulates MLL leukemia stem cell potential by modulating p21 expression. Cancer Res 70: 3833-3842, 2010.

24. Nittner D, Lambertz I, Clermont F, Mestdagh P, Köhler C, Nielsen SJ, Jochemsen A, Speleman F, Vandesompele J, Dyer MA, et al: Synthetic lethality between Rb, p53 and Dicer or miR-17-92 in retinal progenitors suppresses retinoblastoma formation. Nat Cell Biol 14: 958-965, 2012.

25. Hayashita Y, Osada H, Tatematsu Y, Yamada H, Yanagisawa K, Tomida S, Yatabe Y, Kawahara K, Sekido Y and Takahashi T: A polycistronic microRNA cluster, miR-17-92, is overexpressed in human lung cancers and enhances cell proliferation. Cancer Res 65: 9628-9632, 2005.

26. Zhu H, Han $\mathrm{C}$ and Wu T: MiR-17-92 cluster promotes hepatocarcinogenesis. Carcinogenesis 36: 1213-1222, 2015.

27. Zhu H, Han C, Lu D and Wu T: miR-17-92 cluster promotes cholangiocarcinoma growth: Evidence for PTEN as downstream target and IL-6/Stat3 as upstream activator. Am J Pathol 184: 2828-2839, 2014.

28. Wu Q, Luo G, Yang Z, Zhu F, An Y, Shi Y and Fan D: miR-17-5p promotes proliferation by targeting SOCS6 in gastric cancer cells. FEBS Lett 588: 2055-2062, 2014.

29. Park D, Lee SC, Park JW, Cho SY and Kim HK: Overexpression of miR-17 in gastric cancer is correlated with proliferationassociated oncogene amplification. Pathol Int 64: 309-314, 2014.

30. Grillari J, Hackl M and Grillari-Voglauer R: miR-17-92 cluster: Ups and downs in cancer and aging. Biogerontology 11: 501-506, 2010.

31. Krysan K, Kusko R, Grogan T, O'Hearn J, Reckamp KL, Walser TC, Garon EB, Lenburg ME, Sharma S, Spira AE, et al: PGE2-driven expression of c-Myc and oncomiR-17-92 contributes to apoptosis resistance in NSCLC. Mol Cancer Res 12: 765-774, 2014

32. Matsubara H, Takeuchi T, Nishikawa E, Yanagisawa $\mathrm{K}$, Hayashita Y, Ebi H, Yamada H, Suzuki M, Nagino M, Nimura Y, et al: Apoptosis induction by antisense oligonucleotides against miR-17-5p and miR-20a in lung cancers overexpressing miR-1792. Oncogene 26: 6099-6105, 2007.

33. Takakura S, Mitsutake N, Nakashima M, Namba H, Saenko VA, Rogounovitch TI, Nakazawa Y, Hayashi T, Ohtsuru A and Yamashita S: Oncogenic role of miR-17-92 cluster in anaplastic thyroid cancer cells. Cancer Sci 99: 1147-1154, 2008.

34. Ernst A, Campos B, Meier J, Devens F, Liesenberg F, Wolter M, Reifenberger G, Herold-Mende C, Lichter P and Radlwimmer B: De-repression of CTGF via the miR-17-92 cluster upon differentiation of human glioblastoma spheroid cultures. Oncogene 29: 3411-3422, 2010.

35. Olive V, Bennett MJ, Walker JC, Ma C, Jiang I, Cordon-Cardo C, Li QJ, Lowe SW, Hannon GJ and He L: miR-19 is a key oncogenic component of mir-17-92. Genes Dev 23: 2839-2849, 2009.

36. Uziel T, Karginov FV, Xie S, Parker JS, Wang YD, Gajjar A, He L, Ellison D, Gilbertson RJ, Hannon G, et al: The miR-17-92 cluster collaborates with the Sonic Hedgehog pathway in medulloblastoma. Proc Natl Acad Sci USA 106: 2812-2817, 2009.

37. Gupta S, Read DE, Deepti A, Cawley K, Gupta A, Oommen D, Verfaillie T, Matus S, Smith MA, Mott JL, et al: Perk-dependent repression of miR-106b-25 cluster is required for ER stressinduced apoptosis. Cell Death Dis 3: e333, 2012.

38. Gantier MP, Stunden HJ, McCoy CE, Behlke MA, Wang D, Kaparakis-Liaskos M, Sarvestani ST, Yang YH, Xu D, Corr SC, et al: A miR-19 regulon that controls NF- $\mathrm{KB}$ signaling. Nucleic Acids Res 40: 8048-8058, 2012. 
39. Trenkmann M, Brock M, Gay RE, Michel BA, Gay S and Huber LC: Tumor necrosis factor $\alpha$-induced microRNA-18a activates rheumatoid arthritis synovial fibroblasts through a feedback loop in NF- $\kappa \mathrm{B}$ signaling. Arthritis Rheum 65: 916-927, 2013.

40. Li Y, Choi PS, Casey SC, Dill DL and Felsher DW: MYC through miR-17-92 suppresses specific target genes to maintain survival, autonomous proliferation, and a neoplastic state. Cancer Cell 26 262-272, 2014.

41. Li H, Bian C, Liao L, Li J and Zhao RC: miR-17-5p promotes human breast cancer cell migration and invasion through suppression of HBP1. Breast Cancer Res Treat 126: 565-575, 2011.

42. Cohen R, Greenberg E, Nemlich Y, Schachter J and Markel G: miR-17 regulates melanoma cell motility by inhibiting the translation of ETV1. Oncotarget 6: 19006-19016, 2015.

43. Wu Q, Yang Z, An Y, Hu H, Yin J, Zhang P, Nie Y, Wu K, Shi Y and Fan D: MiR-19a/b modulate the metastasis of gastric cancer cells by targeting the tumour suppressor MXD1. Cell Death Dis 5: e1144, 2014

44. Ohyagi-Hara C, Sawada K, Kamiura S, Tomita Y, Isobe A, Hashimoto K, Kinose Y, Mabuchi S, Hisamatsu T, Takahashi T, et al: miR-92a inhibits peritoneal dissemination of ovarian cancer cells by inhibiting integrin $\alpha 5$ expression. Am J Pathol 182: 1876-1889, 2013.

45. Barkan D and Chambers AF: $\beta 1$-integrin: A potential therapeutic target in the battle against cancer recurrence. Clin Cancer Res 17: 7219-7223, 2011.

46. Kato H, Liao Z, Mitsios JV, Wang HY, Deryugina EI, Varner JA, Quigley JP and Shattil SJ: The primacy of $\beta 1$ integrin activation in the metastatic cascade. PLoS One 7: e46576, 2012.

47. Lee YC, Jin JK, Cheng CJ, Huang CF, Song JH, Huang M, Brown WS, Zhang S, Yu-Lee LY, Yeh ET, et al: Targeting constitutively activated $\beta 1$ integrins inhibits prostate cancer metastasis. Mol Cancer Res 11: 405-417, 2013.

48. Somanath PR, Kandel ES, Hay N and Byzova TV: Akt1 signaling regulates integrin activation, matrix recognition, and fibronectin assembly. J Biol Chem 282: 22964-22976, 2007.

49. Dhar S, Gu FX, Langer R, Farokhzad OC and Lippard SJ: Targeted delivery of cisplatin to prostate cancer cells by aptamer functionalized Pt(IV) prodrug-PLGA-PEG nanoparticles. Proc Natl Acad Sci USA 105: 17356-17361, 2008.
50. Dhar S, Kolishetti N, Lippard SJ and Farokhzad OC: Targeted delivery of a cisplatin prodrug for safer and more effective prostate cancer therapy in vivo. Proc Natl Acad Sci USA 108: 1850-1855, 2011.

51. Jacobsen $\mathrm{C}$ and Honecker F: Cisplatin resistance in germ cell tumours: Models and mechanisms. Andrology 3: 111-121, 2015.

52. Jiang Z, Yin J, Fu W, Mo Y, Pan Y, Dai L, Huang H, Li S and Zhao J: MiRNA 17 family regulates cisplatin-resistant and metastasis by targeting TGFbetaR2 in NSCLC. PLoS One 9: e94639, 2014.

53. Wang X, Martindale JL and Holbrook NJ: Requirement for ERK activation in cisplatin-induced apoptosis. J Biol Chem 275: 39435-39443, 2000.

54. Persons DL, Yazlovitskaya EM and Pelling JC: Effect of extracellular signal-regulated kinase on p53 accumulation in response to cisplatin. J Biol Chem 275: 35778-35785, 2000.

55. Mendoza J, Martínez J, Hernández C, Pérez-Montiel D, Castro C, Fabián-Morales E, Santibáñez M, González-Barrios R, DíazChávez J, Andonegui MA, et al: Association between ERCC1 and XPA expression and polymorphisms and the response to cisplatin in testicular germ cell tumours. Br J Cancer 109: 68-75, 2013.

56. Kirschner K and Melton DW: Multiple roles of the ERCC1-XPF endonuclease in DNA repair and resistance to anticancer drugs. Anticancer Res 30: 3223-3232, 2010.

57. Li W and Melton DW: Cisplatin regulates the MAPK kinase pathway to induce increased expression of DNA repair gene ERCC1 and increase melanoma chemoresistance. Oncogene 31: 2412-2422, 2012.

58. Andrieux LO, Fautrel A, Bessard A, Guillouzo A, Baffet G and Langouët S: GATA-1 is essential in EGF-mediated induction of nucleotide excision repair activity and ERCC1 expression through ERK2 in human hepatoma cells. Cancer Res 67: 2114-2123, 2007.

59. Cummings $\mathrm{M}$, Higginbottom $\mathrm{K}$, McGurk CJ, Wong OG, Köberle B, Oliver RT and Masters JR: XPA versus ERCC1 as chemosensitising agents to cisplatin and mitomycin $\mathrm{C}$ in prostate cancer cells: Role of ERCC1 in homologous recombination repair. Biochem Pharmacol 72: 166-175, 2006. 